\title{
POLÍCIA, JUSTIÇA E SOCIEDADE NO BRASIL: UMA ABORDAGEM COMPARATIVA DOS MODELOS DE ADMINISTRAÇÃO DE CONFLITOS NO ESPAÇO PÚBLICO ${ }^{1}$
}

\author{
Roberto Kant de Lima \\ Universidade Federal Fluminense
}

\section{RESUMO}

O autor compara os sistemas jurídicos do Brasil e dos Estados Unidos, particularmente suas instituições do tribunal do júri e o jury, considerando-os loci privilegiados para a produção, reprodução e manutenção da ordem social.

PALAVRAS-CHAVE: sistemas judiciários comparados; produção de verdade no espaço público; tradição inquisitorial; civil law tradition.

\section{APRESENTAÇÃO}

O estudo das teorias e instituições judiciais, em uma perspectiva comparada, pode mostrar como, dependendo do quadro jurídico mais geral, instituições semelhantes podem ter diferentes papéis no que diz respeito à justificação e posicionamento do sistema jurídico frente a modelos e instituições "leigos" de controle social, em diferentes sociedades e culturas. O contraste pode mostrar como diferentes estratégias de reprodução do campo do Direito são reciprocamente determinadas pelos processos de reprodução e mudanças sociais da sociedade como um todo.

Os Estados Unidos, deste ponto de vista, se apresentam para nós como uma referência comparativa potencialmente frutífera, por suas semelhanças estruturais com nossa sociedade, inscritas não só em nossas estruturas políticas, mas também por suas características, também capitalistas, também situadas no Novo Mundo, mas tão distintas das nossas em termos de seus modelos jurídicos de controle social. Modelos que se explicitam tanto nas doutrinas, códigos e leis, como também em nosso dia a dia, nas cotidianas práticas de administrar disputas e promover acordos que

\footnotetext{
1 Versão preliminar deste trabalho foi apresentada à I reunião da Associação Brasileira de Ciência Política (ABCP), realizada no Rio de Janeiro em dezembro de 1998 e aceita para publicação na revista da Associação dos Magistrados do Brasil. Este artigo está também sendo traduzido para o francês para publicação em L es A nnales de la Recherche U rbaine.
}

fazem parte da vida social de qualquer grupo. Tais diferenças, digamos assim, de tradições, ou sensibilidades legais (GEERTZ, 1998) que, explícita ou implicitamente, pretendem produzir a verdade e administrar conflitos, saltam aos olhos quando dirigimos mesmo um rápido olhar para os modelos de controle social no Brasil e nos Estados Unidos, elaborados no âmbito dos respectivos sistemas jurídicos, e que mostram desde logo quão gritantes estas diferenças podem ser.

Contrariamente ao do Brasil, o sistema de controle social dos Estados Unidos se apresenta baseado no pressuposto da origem "local", "popular" e "democrática" da lei e do seu sistema de produção de verdade e resolução de conflitos por negociação e arbitragem. Assim, o campo do Direito tem no trial by jury system e na plea bargaining sua principal instância de legitimação e consagração. As arbitragens pelo júri são representadas como arenas públicas nas quais as categorias legais são reproduzidas e disseminadas, de maneira universal, num processo contínuo e ritualizado, que tem por objetivo declarado a internalização, pelos indivíduos, do direito e das normas de convívio socialmente - ou "politicamente" - corretas 2 .

\footnotetext{
2 Assim, pode-se dizer que, nos Estados Unidos, o sistema legal procura criar e recriar, através da arbitragem pelo jury, um estado de communitas (TURNER, 1974), que não só acaba por recriar uma "estrutura" mas que, durante este processo, promove a identificação homogênea dos seus participantes, como se fossem todos "indivíduos" dotados de uma genérica humanidade.
} 
Estes rituais, amplamente disseminados na mídia, procuram proporcionar a todos uma experiência de renovada igualdade e de homogeneidade social em uma sociedade que se concebe formada por indivíduos cuja diferença é irredutível e que convivem em uma estrutura heterogênea e dividida em classes. A consequiência prática, em termos do posicionamento do campo do Direito frente à estratégia de reprodução de valores sociais, é que este, representado por suas instituições legais, práticas e teorias, se apresenta publicamente como "guardião" dos direitos "naturais" dos indivíduos, bem como dos valores éticos da sociedade, até mesmo - e, às vezes, principalmente - contra o "governo", que é como lá se chama o Estado. A noção de igualdade é, portanto, formal: todos têm direito igual a sua diferença, desde que ela seja expressa em termos aceitáveis pela sociedade local.

Neste modelo, o campo do Direito tende a identificar direito, regras sociais e prescrições morais enquanto constituintes de um sistema de normas geralmente aprovado pela maioria como adequado para o comportamento social em geral. A desobediência à lei — e, por extensão, a qualquer regra social — será identificada socialmente como uma transgressão moral, uma ruptura de um genérico e abstrato contrato social, uma agressão, não a um Estado distante e impessoal, mas aos direitos de outros indivíduos caracterizados como "próximos" física e moralmente, genérica e formalmente iguais, que se estão esforçando para conviver com a diferença alheia.

O espaço público — em inglês, public — aparece assim como um espaço coletivo negociado pelo público que dele faz parte, que pertence ao local e que se compromete a conviver com as diferenças "normais" - quer dizer, aquelas que foram explicitamente discutidas e aceitas — num sistema de segregação dos iguais, mas diferentes, que procura, assim, prevenir explicitamente o conflito latente entre indivíduos únicos com interesses divergentes. A imagem com que essa sociedade prefere se representar é aquela de um paralelepípedo, em que a base é igual ao topo e todos, separadamente, têm direito à mesma trajetória, desigualmente trilhada por cada um dadas suas próprias condições de habilitação e capacitação. Como diz Roberto DaMatta (1979), todos separados, mas juntos.

O que "cola" este sistema de representações é a idéia que ele produz de si mesmo como um mercado de opções, cuja eficácia está fundamentada no acesso universal - quer dizer, de forma igual para todos — dos "consumidores" às informações sobre os "produtos" disponíveis. Este acesso é a garantia da previsibilidade sobre a "normalidade" das escolhas, pois não se pode querer o que não está oferecido explicitamente no mercado. É um sistema em que opções diferenciadas das disponíveis são sistematicamente classificadas como desvios da norma(lidade). Como conseqüência, exige-se que o que é explicitado ao público seja verdadeiro, para que as opções possam ser feitas com conhecimento de causa e haja previsibilidade do comportamento coletivo. O segredo, o saber de acesso particularizado, a informação privilegiada, são elementos profundamente disruptores desse sistema e não podem e não devem produzir resultados válidos, sendo perseguidos e eliminados onde se manifestarem, como representantes confessos do privilégio e da hierarquia excludente. Só é válida em público a informação a que todos têm acesso, sob pena de instaurar-se o caos.

Já no Brasil, ao contrário, o sistema jurídico não reivindica uma origem "popular" ou "democrática". Ao contrário, alega ser o produto de uma reflexão iluminada, uma "ciência normativa", que tem por objetivo o controle de uma população sem educação, desorganizada e primitiva. Os modelos jurídicos de controle social, portanto, não tem nem poderiam ter como origem "a vontade do povo", enquanto reflexo de seu estilo de vida, mas são resultado destas formulações legais especializadas, legislativa ou judicialmente. Nessas circunstâncias não é difícil compreender que, ao não ser considerada como fórmula ideal a "aplicação da lei pelo povo", valores legais, quando se aplicam, tendem a ser vistos como constrangimentos externos ao comportamento dos indivíduos. Em conseqüência, o "capital simbólico" do campo do Direito (BOURDIEU, 1982; 1987), não reproduz ampliadamente seu valor porque expressa a "vontade do povo", ou um conjunto de prescrições morais partilhadas e internalizadas pelo cidadão comum, mas como uma imposição das "autoridades", não importa quão legal e legitimadamente produzidas e postas em vigor.

Difere este modelo ainda daquele comum à civil law tradition, que opera com "códigos" legais legitimados pelo Poder Legislativo, a serem decifrados pelos juristas, pela sua ênfase em processos de "inquirição" como a melhor forma de 
estabelecer a verdade e evitar a explicitação de conflitos na sociedade. Nesta versão do sistema de produção de verdades judiciárias, existe uma valorização positiva explícita do conhecimento detido de forma particular, não universalmente disponível na sociedade: quem pergunta sempre sabe mais do que quem responde e é deste saber que advém a autoridade do seu discurso. Decorrem daí, inclusive, regimes retóricos distintos daqueles da argumentação que busca o consenso: aqui predomina o embate escolástico de teses opostas, em que apenas uma deve ganhar, por ter saber mais autoritativo do que o da outra. Vale o argumento de autoridade, em prejuízo da autoridade dos argumentos.

Neste contexto, a obediência ou a desobediência às leis e regras não se coloca como questão de transgressão moral a regulamentos explícitos facilmente acessíveis, a serem literalmente interpretados, mas como o resultado da escolha entre a liberdade de agir e o constrangimento externo, a opção entre a implementação do desejo individual e da reprodução social de cada um, por um lado, e a submissão a um interesse geral e difuso, quase certamente manipulado em beneficio da reprodução alheia, por outro.

Como conseqüência, aqui, o domínio do público - a res publica, a "coisa pública" contraditoriamente ao domínio da sociedade, não é representado como o locus da regra local e explícita, de aplicação universal, a todos acessível e, portanto, a todos aplicável por igual, que é a condição indispensável e necessária para a interação social entre indivíduos diferentes mas iguais, de acordo com a representação angloamericana da sociedade que, explicitamente, é veiculada naquele sistema. Ao contrário, o domínio do público - seja moral, intelectual ou até mesmo o espaço físico - é o lugar controlado pelo Estado, de acordo com "suas" regras, de difícil acesso e, portanto, onde tudo é possivelmente permitido, até que seja proibido ou reprimido pela "autoridade", que detém não só o conhecimento do conteúdo mas, principalmente, a competência para a interpretação correta da aplicação particularizada das prescrições gerais, sempre realizada através de formas implícitas e de acesso privilegiado. Este é o caso, por exemplo, dos efeitos imprevisíveis que podem ter as coisas "publicadas" no Diário Oficial, que todos tem a "obrigação" de saber e que podem, inclusive, levar alguém a ser julgado e condenado à revelia, isto é, sem que nem mesmo tenha sido pessoalmente informado que está sendo alvo de uma acusação.

O domínio público, assim, é o lugar apropriado particularizadamente, seja pelo Estado, seja por outros membros da sociedade autorizados, ou não, por ele, e, por isso, sempre, aparentemente, opaco, caótico e imprevisível ao olhar coletivo, onde tudo pode acontecer e de onde "quero tudo o que tenho direito", significando não só que reivindico aquilo que sei merecer, mas que desejo ter, substantivamente, tudo o que os outros têm e cujo conteúdo e significação, eventualmente, posso até mesmo desconhecer. A liberdade neste contexto, não é associada à liberdade de escolher no mercado onde as opções dadas foram previamente negociadas, como no sistema anglo-americano, mas à possibilidade aberta de todos poderem "ter" tudo. A idéia de igualdade, assim, torna-se substantiva, associada à semelhança, não à diferença, entre as pessoas (DUMONT, 1974, 1985; DAMATTA, 1979; MAINE, 1861). Neste contexto, as negociações se tornam deslocamentos estruturais, que afetam posições desiguais em uma hierarquia excludente, não composições que visam a produção de uma hierarquia social includente, de um rank.

O espaço público, nesta versão, tem que estar sempre submetido a regras gerais - nunca locais. Neste sentido, é semelhante ao space publique francês - onde o sistema de controle social também rejeita a estratégia das minorias segregadas com lugares diferenciados para preservar a igualdade formal. Estas regras, que não se originam dos cidadãos envolvidos nos conflitos, como devem ser aplicadas particularizadamente, pressupõe uma competição entre os envolvidos pelo favorecimento de sua aplicação e uma suposta neutralidade do aplicador em relação às partes. $\mathrm{O}$ sistema, assim, coloca todos juntos, mas separados e hierarquizados na conquista dos melhores lugares em uma estrutura que pode ser representada como piramidal. E como toda estrutura hierarquizada, piramidal, constituída de partes desiguais mas complementares, esta rejeita a explicitação do conflito, uma força disruptora que ameaça desarrumá-la. Quem está no topo, no vértice, é o único que tudo vê, cuja perspectiva é a verdadeira, pois os demais elementos têm apenas visões parciais do conjunto, tanto mais distorcidas quanto mais próximos à base se encontrem. Só vale a pena saber aquilo que poucos sabem, pois 
só assim tenho a garantia de obter efeitos confiáveis; a informação a que todos têm acesso de nada vale.

Diferentemente do sistema francês, no entanto, há em nosso modelo espaço para o reconhecimento explícito da desigualdade entre os cidadãos, manifestada em nosso dia a dia pelos rituais do "- Você sabe com quem está falando?" e, mesmo, no reconhecimento jurídico a direitos diferentes explicitamente atribuídos a pessoas supostamente desiguais, como é o caso dos privilégios concedidos oficialmente a certas categorias de cidadãos pelo instituto da prisão especial.

O que possibilita, portanto, a ordem social em um sistema que se constrói a partir da explicitação dos conflitos de interesses individualizados, em franca oposição, gerando a construção coletiva de regras explícitas, de aplicação literal e universal, e que se constitui em legitimação de sua ordem jurídica, em que a concepção de igualdade é formal — o direito igual de todos à diferença - é o que dificulta a existência do outro, fundado na conciliação forçada dos conflitos, visando à imposição da harmonia e do status quo, para manter a hierarquia e a complementaridade entre elementos substantivamente diferenciados do sistema, produtor de regras gerais, sempre interpretadas particularizadamente pelos detentores do saber privilegiado para fazer justiça adequada a todos esses segmentos diferenciados.

No primeiro sistema, o acesso universal à informação se constitui na base do controle social, no fator normalizador da sociedade: visa-se não só à repressão das diferenças inaceitáveis, mas o controle da população pela imposição de uma homogeneidade construída pela normalização pela informação: o objetivo do sistema é a neutralização das desigualdades, definidas como meras diferenças. No segundo sistema, o acesso particularizado à informação é o que define a hierarquia das interpretações e as redes de sociabilidade responsáveis pela compensação das desigualdades de toda sorte reconhecidas explicitamente como inevitáveis na sociedade. Não será por coincidência que os contrastes entre os sistemas de educação fundamental no Brasil e nos EUA são tão marcantes, evidenciando lá suas raízes protestantes, em que a capacidade para a leitura e o argumento do acesso universal e literal aos textos sagrados - e, consequentemente, àqueles responsáveis pela ordem na sociedade - são requisitos indispensáveis para a incorporação dos segmentos reconhecidamente diferenciados da população e para a compreensão do seu papel na administração e controle da diversidade dos homens no mundo (LINDHOLM, 1997).

A estratégia que adotarei para analisar as categorias do discurso presentes nas tradições jurídico-políticas - ou sensibilidades jurídicas - do Brasil e dos Estados Unidos parte, assim, do pressuposto de que essas tradições, produzidas e reproduzidas nos textos jurídicos, são partilhadas por aqueles que a elas têm acesso através das instituições escolares ou pelos processos de socialização presentes na participação em procedimentos jurídicos ou judiciários. Assim, tais tradições servem, seguramente, de "referência" para — ou "modelo para" (GEERTZ, 1978) - o comportamento dos profissionais e leigos envolvidos, o que empresta a suas ações o mínimo necessário de previsibilidade, garantindo-lhes um mínimo de eficácia. Neste sentido, as Faculdades de Direito no Brasil e nos EUA, os julgamentos brasileiros, as bargains e as arbitragens pelo jury dos Estados Unidos atualizam tais valores, constituindo-se em loci privilegiados de legitimação e consagração das estratégias preconizadas no modelo jurídico de controle social.

Não é de menor importância relembrar que essas tradições jurídicas não limitam sua existência e influência aos profissionais da área. Nos tribunais, a população em geral participa, seja como "partes" ou "testemunhas" nas ações judiciais, seja como "juizes leigos" — jurados — das atividades judiciais, socializando-se em seus procedimentos e legitimando sua existência. Aliás, poder-se-ia dizer, mesmo, que o júri/jury, no campo do Direito, tanto no Brasil como nos Estados Unidos, se constitui em uma das suas problemáticas obrigatórias (BOURDIEU, 1987, p. 207), questões que devem ser compulsoriamente abordadas de pontos de vista divergentes e que têm o efeito de tornar os participantes dos debates contemporâneos em suas discordâncias.

Isto tem uma importância estratégica para a nossa discussão, porque ambos os discursos concordam, em principio, em identificar os fundamentos desta instituição judicial com a responsabilidade pela "participação popular na administração da justiça". Assim, é exatamente no discurso sobre o júri/jury que o campo do Direito vai definir sua posição em relação à sociedade e à 
cultura, no Brasil e nos Estados Unidos. Ora, dado que a referida instituição tem "versões" e relevância inteiramente distintas nestas sociedades, estas distinções podem ser utilizadas para fazer uma reflexão sobre a posição ocupada pelo campo do Direito em cada uma delas, tendo sempre em mente suas vinculações profundas com o campo político e sua posição particular de formulador de modelos dominantes para a produção, reprodução e manutenção da ordem social.

Finalmente, devo advertir que o argumento deste trabalho está fundamentado em análise do discurso jurídico presente em textos legitimados e consagrados dos campos do Direito no Brasil e nos Estados Unidos. Neste sentido, consideramos este discurso como uma parte da realidade social, que ajuda a lhe emprestar significados e referências semânticas. Evidentemente, há toda uma parte do comportamento dos juristas, jurados e cidadãos comuns, que escapa à nossa análise, dadas as limitações necessariamente impostas a este tipo de trabalho. Afinal, como na fábula sobre o "País dos Cartógrafos" de Jorge Luis Borges, os cientistas sociais nada mais fazem do que mapas do real, sendo inúteis, por definição, mapas do tamanho daquilo que querem descrever ou modelos que pretendam repetir o real, como também nos ensinou Lévi-Strauss (1970).

Deve-se dizer, no entanto, que nestes últimos quinze anos venho realizando investigações nesta área que, além de pesquisa bibliográfica e arquivística, envolveram trabalho de campo e observação participante com instituições acadêmicas, judiciais e policiais, no Brasil e nos Estados Unidos, cujos resultados estão parcialmente publicados, aqui e lá (por exemplo, KANT DE LIMA, 1995a; 1995b; 1997a; 1997b) e que tal material está incorporado, voluntária ou involuntariamente, consciente e inconscientemente, como quadro de referência em que se desenvolve o argumento, impondo-lhe limites e, espero, corrigindo seus eventuais excessos. É claro, também, que o inconsciente do pesquisador sempre é parte de seu trabalho, como há muito já proclamou a Escola Sociológica Francesa (LÉVI-STRAUSS, 1950; 1970; MAUSS, 1950). Assim, embora com essas limitações metodológicas, acredito que a explicitação esquemática das referências contrastantes desses discursos jurídicos que passarei a fazer seja importante para a compreensão dos significados culturais atribuídos ao efetivo comportamento dos membros dessas duas sociedades, tarefa precípua, a meu ver, da análise e interpretação sociológica.

II. O SISTEMA JUDICIÁRIO PENAL COMO UM SISTEMA DE ADMINISTRAÇÃO DE CONFLITOS PELA PRODUÇÃO DE VERDADES: A REFERÊNCIA COMPARATI$\mathrm{VA}^{3}$

O sistemas judiciários têm uma de suas principais ênfases na administração de conflitos na sociedade. Entretanto, não são unânimes as formas que sua administração deve tomar, pois estão relacionadas a diferentes tradições culturais que, por exemplo, ora vêem nos conflitos fonte de desordem e de quebra da harmonia social, a ser reprimida ou exemplarmente punida, ora vêem nos conflitos, considerados inevitáveis para a vida social, fonte de ordem quando devidamente solucionados.

Assim, instituem-se verdadeiros sistemas de verdade ou regimes de verdade, que são responsáveis pela produção das prestações judiciárias encarregadas de administrar conflitos. Normalmente, tais regimes são apresentados como tendo se sucedido no tempo, a existência de um eliminando a existência do outro ou até mesmo sendo suplantados por sistemas de controle extra ou para-jurídicos (FOUCAULT, 1974; 1977). Argüirei aqui que isto não é necessariamente verdadeiro, tomando como exemplo, respectivamente, o sistema brasileiro, onde diferentes desses sistemas convivem, de forma mais ou menos explícita, concomitantemente, e são alternada e alternativamente utilizados pelos operadores judiciais, e aqueles vigentes nos sistemas judiciários criminais dos Estados Unidos, que incorporaram técnicas e estratégias normalizadoras.

Ora, se isso é verdade, embora o sistema jurídico continuasse a afirmar seu caráter universalista na aplicação das mesmas regras a todos, esta concomitância e a possibilidade implícita de alternância, implicaria, certamente, a aplicação de diferentes regras a diferentes "casos" ou a diferentes "partes" em conflitos semelhantes a serem igualmente administrados pelo mesmo Estado.

Para levar esta tarefa a bom termo, será necessário estabelecer certas referências comparativas, que coloquem em contraste diferentes sistemas judiciários - sistemas de produção de provas ou de verdades judiciárias. Para o propósito deste

3 Sigo aqui, em parte, a argumantação que desenvolvi em KANT DE LIMA, 1997. 
texto, deverei tomar os sistemas de justiça criminal do Brasil e dos EUA como referências. De novo, devo enfatizar que a perspectiva comparada que pretendo utilizar será de caráter contrastivo, buscando as diferenças e, não, as possíveis semelhanças entre os sistemas, para perceber, dentro de suas especificidades, suas equivalências enquanto sistemas de produção de verdades judiciárias. Isto quer dizer que comportamentos, instituições e categorias semelhantes podem ter diferentes significados e papéis; e vice-versa, elementos diferentes podem ter papéis e significados semelhantes.

Finalmente, devo novamente insistir em que interessa ao antropólogo compreender e explicitar os princípios de funcionamento dos diferentes sistemas ou regimes de verdade, não estando em pauta, aqui, o julgamento de qual sistema é superior, ou inferior, ao outro.

Ora, o regime de verdade do criminal justice system dos EUA repousa sobre a idéia de que a verdade é fruto de uma decisão consensual sistematicamente negociada. Isto vale tanto para a barganha que se faz entre a promotoria e a defesa, quando o réu se declara culpado - plea guilty, plea bargain - quanto para a decisão que encerra a arbitragem, pelo Judiciário, dos conflitos em que o réu insiste em se declarar não culpado - not guilty. Neste último caso, constrói-se também a verdade pela negociação, pois o Estado tem por obrigação colocar à disposição do acusado um processo legal específico - o due process of law - que terminará, se o defendant insistir até em afirmar que está sendo injustamente acusado, em um veredict, o qual nada mais é do que uma decisão tomada pelos jurados, negociada, por maioria ou por unanimidade, em um processo público de discussão, entre eles, até chegarem a uma conclusão satisfatória para todos. Como são em número par (doze), sempre existe a possibilidade do empate, caso em que não há decisão, sendo o caso encaminhado a nova arbitragem.

Então, a verdade pública produzida para administrar conflitos é, explicitamente, fruto de: (a) uma negociação patrocinada pelo District Attorney Office (promotoria) - uma barganha em que cada uma das partes desiste de sua verdade para compor uma terceira versão satisfatória para todos - ou de, alternativamente, (b) uma negociação no âmbito do judiciário, entre os jurados, árbitros selecionados pelas partes para decidir qual a verdade que vão dizer ao público, depois de presenciarem a exposição dos fatos admitidos em juízo - seu veredict (vere dictum).

Este último sistema, no âmbito do judiciário dos EUA, é denominado de trial by jury, e é considerado um desdobramento - ou, como costumam dizer os juristas, de maneira equivocada, uma "evolução" — de outros sistemas judiciários, que tinham ou no sistema de "prova legal", ou no inquest, seus principais fundamentos.

Como se sabe, o sistema de "prova legal" era uma espécie de regulação da guerra, em que não importavam os fatos ou testemunhos do conflito, mas a escolha divina de uma das partes como vencedora de um determinado teste. Já o inquest era um sistema - denominado de "racional" por oposição ao da "prova legal" - em que eram tomados testemunhos em interrogatórios de resposta obrigatória para aqueles que tinham conhecimento dos fatos.

Ora, a tradição judicial dos EUA considera que esses dois sistemas de verdade foram substituídos lá, por um terceiro, de arbitragem pelo júri. São características deste sistema a presunção da inocência — pois só vão a julgamento os acusados que não se declaram culpados, a quem o Estado deve $\mathrm{o}$ due process of law - ou seja as arbitragens pelo júri nunca são obrigatórias para os cidadãos; o direito de não se incriminar, que impõe ao silêncio o significado da não culpabilidade, tendo como correlata a obrigação de dizer a verdade tudo o que todos dizem em juízo deve ser verdade, sob pena de cometerem o crime de perjury; e a escolha, em comum acordo, dos "fatos" que devem ser discutidos e validados diante dos jurados, excluindo-se aqueles que não são consensualmente aprovados, através das exclusionary rules. $\mathrm{O}$ procedimento é todo oral $\mathrm{e}$ as falas são transcritas literalmente, servindo, a partir daí, de documentos para futuras discussões em outras instâncias. Assim, a oralidade, a explicitude e a literalidade são as suas características fundamentais.

Por outro lado, o sistema do D.A. também é considerado um desdobramento do direito de os cidadãos negociarem com o Estado sua culpa, quando o desejassem, uma vez que a promoção pública ou privada das acusações, até o início deste século, não era obrigatória no sistema legal dos EUA (STEINBERG, 1984; 1989). Tanto a polícia, 
como a promotoria, têm o direito - e o dever de barganhar com os acusados, pressionando-os para desistirem de seu direito a um due process of law, declarando-se culpados de um crime menor sob a ameaça de serem levados a juízo por um crime maior e correrem o risco de serem por este condenados, inapelavelmente. A justificativa explícita deste procedimento é a sua "economia processual", pois a arbitragem pelo juri é muito dispendiosa para o judiciário e para as partes. $\mathrm{O}$ que está em jogo, portanto, não é o que os acusados efetivamente fizeram, mas quais as suas possibilidades de negociação com o sistema. Além disso, embora a promoção não seja mais facultativa ao Executivo, a promotoria só acusa quando acha que pode vencer o caso. Caso contrário, não deve tomar a iniciativa de promover a arbitragem pelo Judiciário: ou deixa o caso em aberto ou faz uma barganha.

O mais importante para reter, no entanto, é que apesar das diversas críticas que este sistema sofre, seja por ser mais injusto com as partes mais fracas, seja por apresentar soluções diferentes para conflitos através de duas instituições, o Judiciário — com seu due process of law - e a promotoria e a polícia - com as suas diferentes bargains é que a sua lógica é una, inequívoca e universalmente disponível: a verdade pública é fruto de uma negociação explícita e sistemática entre as partes interessadas.

\section{O SISTEMA JUDICIÁRIO CRIMINAL BRASILEIRO: CARACTERÍSTICAS GE- RAIS}

Ora, por contraste com esta lógica universal e unívoca, o sistema brasileiro nos apresenta um mosaico de "sistemas de verdade", tanto em suas disposições constitucionais, como em suas disposições judiciárias e policiais. Mais ainda, por não reconhecer, explicitamente, que tais sistemas existem, o sistema judicial criminal permite que estas diferentes lógicas sejam usadas alternativa e alternadamente, embora as verdades por elas produzidas se desqualifiquem umas às outras, o que redunda em verdadeira "dissonância cognitiva", tanto para os operadores do sistema como para a população em geral.

Estas diferentes disposições podem coexistir porque, por um artifício da chamada "dogmática jurídica", as normas jurídicas encontram-se hierarquizadas e se anulam automática e reciprocamente quando entram em contradição, observando-se, para resolver os conflitos entre elas, a rígida hierarquia em que, teoricamente, se encontram dispostas. Esta doutrina, portanto, como todo conhecimento dogmático, não deixa espaço para que se explicitem as diferentes tradições e a sua história, que imprimem significados distintos a procedimentos semelhantes.

No topo desta hierarquia de normas temos os princípios constitucionais. Estes, aparentemente, são assemelhados àqueles do due process of law dos EUA: asseguram a presunção da inocência, o direito à defesa - chamado de princípio do contraditório - conferindo, entretanto, um outro direito, chamado de ampla defesa, pelo qual os acusados podem e devem usar todos os recursos possíveis em sua defesa. Ora, este sistema traz em si algumas contradições: a primeira é que não é um due process of law - expressão erroneamente traduzida em português de forma demasiado livre e apressada como "devido processo legal" - pois esta instituição jurídico-política dos EUA é uma opção do acusado, a quem é devido, pelo Estado, um determinado procedimento judicial, em condições estipuladas pela quinta e sexta emenda constitucionais, que incluem, entre outros, o direito a um speedy trial — um julgamento rápido, o que não existe em nosso sistema de julgamentos obrigatórios e de temporalidade própria; a segunda é que, não havendo exclusionary rules — regras de exclusão das evidências levadas a juízo, nem uma hierarquia de provas - que separe, ao final do julgamento, os fatos provados daqueles que não o foram - tudo, literalmente, pode ser alegado em defesa - ou em acusação - no processo, o que produz uma parafernália de elementos tanto mais ampla quanto mais abundantes forem os recursos do acusado e dos acusadores; finalmente, ao assegurar constitucionalmente o direito de o acusado não se auto-incriminar (direito ao silêncio), não se criminaliza, como no direito anglo-americano, a mentira dita pelo réu em sua defesa, o que implica não haver, no Brasil, a possibilidade de condenação por perjury, somente por falso testemunho ${ }^{4}$.

4 Recentes acontecimentos envolvendo o comparecimento de um ex-presidente do Banco Central do Brasil a uma Comissão Parlamentar de Inquérito (CPI) do Legislativo demonstraram claramente essa contradição, habilmente explorada pelo advogado da "testemunha", já meio réu no procedimento legislativo, e futuro acusado em processo judicial, no qual terá, legal, legítima e alternativamente, o direito de dizer a verdade, de mentir ou de permanecer calado, enquanto réu. 
A seguir, temos o Código de Processo Penal, que regula três formas de produção da verdade: a policial, a judicial e a do Tribunal do Júri. Tais formas encontram-se, no Código, hierarquizadas explicitamente: no inquérito policial o procedimento da polícia judiciária, oficialmente, é "administrativo", não judicial e, por isso, inquisitorial, não se regendo pelo princípio do contraditório; o procedimento judicial aplica-se à maioria dos crimes, e inicia-se, obrigatoriamente, quando há indícios suficientes de que um delito foi cometido e que sua autoria é presumida, com a denúncia da promotoria dando oportunidade à defesa, pois se regula pelo princípio do contraditório até a sentença do juiz que exprime seu convencimento justificado pelo exame do conteúdo dos autos; e, finalmente, o julgamento pelo Tribunal do Júri é um procedimento que se aplica apenas aos crimes intencionais contra a vida humana e se inicia por uma sentença judicial proferida por um juiz (pronúncia), após a realização da produção de informações, indícios e provas, durante o inquérito policial e a instrução judicial, comum a todos os processos judiciais criminais e também regida pelo contraditório e pela ampla defesa, em um processo que exige a presença do réu e que termina pelo veredito dos jurados. Há outros procedimentos, vinculados à diferente natureza das infrações, que deixo para analisar em outra oportunidade.

Em sua "Exposição de Motivos", o Código de Processo Penal também explica que o objetivo do processo judicial criminal é a descoberta da "verdade real", por oposição à "verdade formal" do processo civil, quer dizer, aquela que é levada ao juiz, por iniciativa das partes. Por isso, os juízes podem e devem tomar a iniciativa de trazer aos autos tudo o que pensarem interessar ao processo, ex-officio, para formar o seu "livre convencimento" examinando a "prova dos autos", quer dizer, todos os elementos que se encontram registrados, por escrito, nos volumes que formam os processos judiciais e os inquéritos policiais. Como já disse, não há, no direito brasileiro, uma hierarquia explícita e obrigatória de provas, podendo ser examinados todos os elementos que constarem do processo, inclusive os resultantes não só da iniciativa do juiz, como das partes, no exercício do direito constitucional de acusação e ampla defesa, na busca da verdade beyond any doubt.

\section{III.1 O INQUÉRITO POLICIAL}

De acordo com um delegado de polícia, entre- vistado durante a pesquisa, o inquérito policial é "um procedimento do Estado contra tudo e contra todos para apurar a verdade dos fatos". Assim, o inquérito policial é um procedimento no qual quem detém a iniciativa é um Estado imaginário, todo poderoso, onipresente e onisciente, sempre em sua busca incansável da verdade, representado pela autoridade policial, que, embora sendo um funcionário do Executivo, tem uma delegação do Judiciário e a ele está subordinado quando da realização de investigações.

O procedimento judiciário policial, portanto, pode ser inquisitorial, conduzido em segredo, sem contraditório, porque ainda não há acusação. Entretanto, embora não seja legalmente permitida a negociação da culpa, ou da verdade, neste nível - como, aliás, em nenhum nível do processo criminal, que está em busca da "verdade real", como se viu - é lógico que a polícia barganha, negocia, oficiosa e/ou ilegalmente, em troca de algum tipo de vantagem, tanto o que investiga, como o que os escrivães policiais escrevem nos "autos" do inquérito policial, o que se denomina, mesmo, por uma categoria específica: a "armação do processo".

Tais procedimentos, sempre ameaçados de ilegalidade, são sempre analisados ou como distorções, ou como desvios de comportamento, atribuídos a funcionários inescrupulosos. Entretanto, embora isto possa ser em alguns casos verdade, observei durante a pesquisa de campo certas regularidades que apontam para a consistência de tais procedimentos com um verdadeiro sistema de produção de verdade, de eficácia comprovada. Assim, a regulação da tortura de acordo com a gravidade da denúncia ou queixa e conforme a posição social dos envolvidos; a permissão da participação dos advogados nos inquéritos também de acordo com as diferentes posições que estes especialistas ocupam nos quadros profissionais; o registro - ou não — das ocorrências levadas ao conhecimento da polícia; a qualificação e tipificação - ou não - das infrações e crimes registrados e a abertura de investigações preliminares, que levam, ou não, ao arquivamento ou prosseguimento do inquérito policial; tudo isso de acordo com interesses manifestamente particularistas são, sem dúvida, algumas dessas práticas institucionalizadas (KANT DE LIMA, 1995).

Ora, muito depois de ter tido contato com tais práticas durante o trabalho de campo, pesquisas 
arquivísticas complementares, orientadas por colegas especialistas em história do processo, mostraram que os procedimentos observados eram muito semelhantes aos da "inquirição-devassa" do Direito português ou da inquisitio do Direito Canônico: um procedimento sigiloso, que preliminarmente investiga, sem acusar, visando obter informações sobre perturbações da ordem denunciadas pública ou anonimamente; depois, averiguados os fatos, chama-se o suposto responsável para interrogá-lo, perguntando-lhe sobre o que já se sabe sobre ele, objetivando levá-lo a confessar; se o crime é leve e o acusado confessa, é repreendido, apenas; se o acusado não confessa, ou se o crime é grave, o acusado é "indiciado" e o processo é encaminhado à justiça criminal.

Estes procedimentos se justificavam em sociedades onde a desigualdade substantiva entre as partes era explícita: não se desejava manchar a reputação de homens de honra que podiam ser injustamente acusados, nem se desejava expor os despossuídos à ira dos poderosos por eles maldosamente denunciados: o Estado, então, compensava essa desigualdade, assumindo a iniciativa da descoberta da verdade (MENDES DE ALMEIDA Jr., 1920). Aqui, é evidente a produção de um ethos de suspeição sistemática motivado pelo desejo de evitar ou abafar a explicitação de conflitos, ou de punir aqueles que neles se envolvem, prejudicando a harmonia de uma sociedade de desiguais complementares, onde cada um tem o seu lugar.

\section{III.2 O PROCESSO JUDICIAL}

Já vimos que o processo judicial se inicia pela denúncia do promotor - uma acusação pública que gera defesa - seguindo-se o interrogatório do acusado, agora réu. Neste interrogatório defesa e acusação não participam, ou participam apenas como assistentes. É um procedimento que se autojustifica como sendo em defesa do réu, nitidamente inquisitorial, em que o juiz adverte, obrigatoriamente, o acusado, de que "seu silêncio poderá resultar em prejuízo de sua própria defesa", teoria e prática que parecem colocar-se, como já disse, nitidamente, em contradição com a presunção da inocência identificada ao silêncio do réu e ao direito de não se incriminar do dispositivo constitucional ${ }^{5}$.

50 direito de não se incriminar substituiu na tradição anglo-americana the right to stay mute, que era 0 direito de nada declarar diante das acusações formuladas
Em compensação, se o silêncio pode vir em prejuízo da própria defesa - como diz o brocardo, quem cala, consente - o réu pode mentir livremente, pois apenas as pessoas verdadeiramente arrependidas confessam a verdade. $\mathrm{O}$ crime de "falso testemunho", diferentemente do crime de perjury, só pode ser alegado contra as testemunhas. Note-se também que a auto-acusação, quer dizer, a negociação da culpa pela admissão falsa de crime menor com o intuito de safar-se de crime maior, tradicionalmente punida pelo Direito eclesiástico (BOSCHI, 1987), também é punida pelo Código Penal, o que contrasta tanto com a police bargain, quanto com a plea bargain do sistema judicial criminal dos EUA.

A seguir, "reperguntam-se" todas as testemunhas que já depuseram na polícia, com a assistência oficial e legal da defesa e da acusação. Tal assistência, obviamente, varia de acordo com as posses do acusado e se reflete no comparecimento qualificado — ou na ausência dele — das testemunhas do processo. Por várias circunstâncias (mudanças de residência e/ou de status social e civil, dificuldade de locomoção, doenças, mortes etc.) são, em geral, as pessoas de melhor condição econômica ou, pelo menos, os réus soltos, que conseguem trazer, de novo, as mesmas testemunhas, assim como outras novas, para depor.

Embora se diga que este processo não é conduzido pelo juiz, mas pelo Ministério Púbico, não caracterizando, assim, um inquérito judicial propriamente dito, a ênfase no papel do juiz é manifesta, seja na iniciativa a ele atribuída de buscar a verdade real, crível além de qualquer dúvida, seja na condução exclusiva do interrogatório do réu, seja na tomada do depoimento das testemunhas, porque o juiz sempre pode interpretar as respostas dos ouvidos e interrogados ao escrivão, ditando-as ou mandando-as transcrever para registro nos autos.

Durante o processo judicial, o réu pode per-

publicamente e assim escapar a qualquer tipo de avaliação judicial, embora sujeitasse quem dele se servia à "la peine forte et dure", que terminava por, eventualmente, matálo. Para evitar isso, quando o acusado se calava diante das acusacões, convencionou-se que seu representante, por ele, declarava-se not guilty, o que dava prosseguimento ao processo. 0 silêncio, assim, formalmente, significa 0 oposto do que em nossa tradição, onde "quem cala, consente". 
manecer preso ou em liberdade. Nos EUA, a fiança é a forma de soltar os réus e, como lá a ideologia é igualitária, aponta-se, por isso, forte discriminação econômica, pois os mais pobres tem sua defesa prejudicada, não só em função de seu pior estado psicológico, como também por não poderem produzir provas para sua defesa. Já no Brasil se as fianças não são caras, essa desigualdade se inscreve nos autos do inquérito policial - em que se registram as investigações contra os mais pobres, feitas sem advogado ou contra os mais ricos, armadas por eles com o consentimento da polícia. Esses depoimentos e confissões, registrados por escrito, estão entranhados nos autos pela não interrupção da numeração seqüencial de suas páginas, podendo servir ao convencimento do juiz (KANT DE LIMA, 1995).

Além disso, importantes dispositivos legais de diferenciação de tratamento dos acusados, no Brasil, são a "prisão especial", que assegura condições privilegiadas na prisão, concedidas a certas categorias de pessoas, que vão desde a permanência em separado dos chamados "presos comuns", em acomodações especialmente destinadas a isto, até a "prisão domiciliar", cumprida na residência do acusado; e a "competência por prerrogativa de função", que retira certos acusados do âmbito do julgamento preconizado para os cidadãos "comuns", pelo juiz singular ou pelo júri, enviando-os para julgamento por seus supostos "pares", situados em órgãos judiciais colegiados de instâncias superiores, como os Tribunais de Justiça e os Tribunais Superiores de terceira instância, ou o Supremo Tribunal Federal, mesmo no caso de terem cometido infrações comuns sem relação com suas atividades profissionais, como se o privilégio não fosse da função, mas da pessoa.

Finalmente, o juiz decide de acordo com seu "livre convencimento", fundado no conteúdo dos autos, os quais, como apontei, trazem entranhados os registros do inquérito policial, com os depoimentos e confissões obtidas na polícia sem a presença oficial da defesa. À oralidade, literalidade e explicitude de critérios de produção de fatos válidos dos procedimentos judiciais dos EUA, os procedimentos brasileiros apontam para o privilegiamento da escrita, da interpretação e da implicitude. O juiz — não mais o Estado, como no inquérito policial - é visto como um agente extremamente esclarecido, quase clarividente, capaz de formular um julgamento racional, imparcial e neutro, que descubra não só a "verdade real" dos fatos, mas as verdadeiras intenções dos agentes. É interessante notar que nesse contexto de formulação de "certezas jurídicas", como aponta Malatesta (1911), num sistema como esse, tentase minimizar aquilo que poderia assegurar ao juiz e ao público o absoluto acerto de sua "sentença": a confissão.

Nos casos dos crimes intencionais contra a vida humana, no entanto, o juiz singular não dá a palavra final. Nesses casos, ele formula uma sentença que "pronuncia" ou "impronuncia" o réu. Quando a sentença pronuncia o acusado, seu nome é inscrito no "rol dos culpados", registro do qual só sairá se absolvido no processo. Inicia-se, então, o julgamento pelo Tribunal do Júri.

\section{III.3 O JULGAMENTO PELO TRIBUNAL DO JÚRI}

Embora a maioria da literatura especializada procure estabelecer equivalências entre este nosso procedimento judicial e aquele da tradição angloamericana (FRANCO, 1956; MARGARINOS TORRES, 1939), tais semelhanças são extremamente superficiais ${ }^{6}$. Para começar, o nosso julgamento não é uma opção do acusado, como o do trial by jury, que é aplicado apenas aos que se declararem inocentes. A seguir, porque aqui ele é a culminância de vários procedimentos em que o acusado foi progressiva e sistematicamente indiciado na polícia e sucessivamente denunciado e indiciado no processo judicial, decidindo-se, finalmente, "pronunciá-lo" e inscrever seu nome no "rol dos culpados". A presunção oficiosa, portanto, é de culpa, não de inocência. Note-se, também, que o due process of law é um procedimento constitucional universalmente disponível aos cidadãos, para ser aplicado de acordo com leis locais, que devem ser a todos os do lugar igualmente aplicadas. A universalidade depende, portanto, da definição do universo e do espaço público, coletivo, sempre limitado, ao qual se aplica em todos casos em que é devido pelo Estado. Em nosso caso, esta é uma instituição judiciária que se aplica obrigatoriamente, mas apenas a certos crimes, quando se faz a aplicação particularizada de uma lei geral — feita pelo legislativo federal - a casos específicos.

\footnotetext{
6 Para uma excelente comparação entre os rituais do júri dos EUA e os julgamentos franceses, que se assemelham aos brasileiros, ver GARAPON, 1997.
} 
No trial by jury ${ }^{7}$ o juiz é o árbitro das regras de admissão de evidência que se apresentam, todas, durante o julgamento. Aqui, como já mencionei, o juiz é que está obrigado a procurar, por sua iniciativa, a "verdade real" e se encontra obrigado, pelos critérios da "ampla defesa", à aceitabilidade de todas as evidências e indícios trazidos pelas partes ao processo, sob pena de provocar suas reações, passíveis de prejudicar a sua validade. O juiz lê os autos e os relata para os jurados, que dificilmente têm contato com seu conteúdo de outra forma: seu conhecimento sobre os fatos, enquanto operadores judiciais, portanto, é de segunda ou terceira mão. Também diferem os procedimentos na tomada de depoimentos: nos EUA são feitas questions durante a examination e crossexamination do acusado - que consentiu em depor - e das testemunhas, que não podem ser "interrogadas" - quer dizer, não podem ser perguntadas pelo que se supõe que elas sabem, ou deviam saber - nem podem ter suas respostas induzidas; aqui, ao contrário, há um interrogatório obrigatório do réu, baseado no que foi apurado durante o inquérito policial e a instrução judicial e não há regras para a tomada de depoimento de testemunhas.

Os árbitros, lá, são doze pessoas cuidadosamente selecionados de comum acordo entre defesa e acusação, apenas para aquele julgamento, dentre listas amplas de todos os eleitores ou de todos os residentes. Aqui, são sorteados de uma lista preparada anualmente, de antemão, pelo juiz, composta de pessoas de sua confiança ou a ele indicadas por pessoas ou instituições fidedignas, da qual se sorteiam vinte e um por mês e, destes, sete para cada julgamento. Defesa e acusação tem direito a três recusas, sem justificação, cada.

O julgamento, aqui, verifica-se, em geral, em uma sala especialmente preparada, diante de uma platéia, que se senta de frente para o juiz, sobre cuja cabeça está, tradicionalmente, um crucifixo católico, representando a humanização da justiça ${ }^{8}$. $\mathrm{O}$ promotor localiza-se, ora à direita, ora à esquerda do juiz, de frente para a platéia, e um escrivão senta-se do outro lado do juiz. Sentados em duas filas, junto a uma das paredes laterais,

7 Para uma discussão sobre as diferenças entre exame e inquérito ver FOUCAULT, 1974; e 1977.

8 Sobre a importância deste crucifixo, veja-se TORRES, 1939. ficam os jurados, geralmente vestidos com uma espécie de pequena beca, à maneira dos outros serventuários da Justiça. Junto à parede oposta, de frente para os jurados, senta-se o advogado, acima do réu, acomodado, também diante dos jurados, no chamado "banco dos réus". Muitas vezes promotor e jurados ocupam o mesmo lado da sala, como no I Tribunal do Júri do Rio de Janeiro

Embora possa apresentar variantes, dependendo das orientações particulares de cada Juiz Presidente do Tribunal do Júri e da época em que o espaço do Tribunal foi construído, esta disposição inquisitorial do espaço contrasta fortemente com disposição adversarial do trial by jury, onde o acusado e sua defesa sentam-se lado a lado à acusação, de frente para o juiz e de costas para a platéia, tendo a um de seus lados os jurados, sentados na jury box. Caracteriza-se, assim, espacialmente, a igualdade ideológica entre as partes, considerando-se a promotoria como uma parte igual às outras, o que reforça a presunção ideológica de inocência, só passível de alteração por uma reasonable doubt (dúvida razoável), reconhecida pelos jurados.

No Brasil, o julgamento se inicia, após o sorteio e o compromisso dos jurados, por novo interrogatório do acusado. Após este procedimento, podem-se ouvir novas testemunhas, o que dificilmente ocorre, a não ser em julgamentos muito especiais. Dificilmente se ouvem, outra vez, as antigas - a não ser que tenham sido convencidas a mudar de opinião, pois há uma crença generalizada de que elas tendem a "atrapalhar" a argumentação de advogados e promotores, "confundindo" os jurados.

A parte mais importante do julgamento, portanto, é um debate, em que acusação e defesa se defrontam, durante duas horas, cada uma, com a possibilidade de prorrogação por mais uma hora, cada. Nesta verdadeira disputatio escolástica, os advogados e os promotores defendem "teses" opostas, que não podem encontrar-se jamais, sob pena de declarar-se "inepta" a defesa. Quer dizer, mesmo quando acusação e defesa concordam com a culpa ou com a inocência do acusado, têm que acusá-lo e defendê-lo em público, apresentandose suas teses em oposição. A verdade, assim, não é construída a partir de um consenso, mas aparecerá com o resultado de um duelo, em que vencerá o mais forte, ou o "escolhido por Deus", 
como rezava a antiga tradição do sistema de provas legais.

Os advogados também não costumam se ater aos autos, pois não ficam registros escritos de suas falas, diferentemente do procedimento dos EUA. Também podem mentir, pois estão sustentando a versão de um acusado que tem direito de continuar a mentir em causa própria durante seu novo interrogatório. Por isso, o conteúdo dos autos, embora lido em suas principais partes pelo juiz, em seu relatório, é posteriormente manipulado livremente tanto pela acusação quanto pela defesa.

Após este verdadeiro espetáculo quase teatral, sem que lhes tenham sido esclarecidos oficialmente quais os fatos efetivamente provados do processo, nem as suas implicações legais, como é obrigatório nos EUA, os jurados se recolhem a uma sala secreta, sem a presença do réu, na companhia do juiz, de um serventuário da justiça - que os acompanhou todo o tempo do julgamento para que não se comunicassem entre si nem com o público - , de representantes da defesa e da acusação - o que difere da reunião secreta para discussão do processo e negociação do verdict dos doze jurados nos EUA, à qual ninguém pode assistir. Aí, novamente proibidos de discutir entre $s i$, votam, secretamente, de acordo com sua consciência, colocando cédulas marcadas com sim ou não em uma urna em resposta a uma série de perguntas extremamente técnicas, que incluem o exame de agravantes e atenuantes, formuladas pelo juiz, com a anuência da acusação e da defesa (a quesitação), diferentemente do guilty/not guilty da arbitragem dos EUA.

Mais uma vez, o ritual da produção da verdade se revela distinto. Diferentemente da incomunicabilidade dos jurados dos EUA, que podem ser segregados para não se comunicarem com os outros segmentos da sociedade, mas que devem formar sua opinião, sua verdade coletiva, em conjunto, pelo consenso, muitas vezes de unanimidade obrigatória, a ser obtida entre doze pessoas, aqui a justificativa para a incomunicabilidade dos jurados entre si é a de que as pessoas, sozinhas, decidem melhor do que em conjunto, pois em conjunto podem influenciar-se uns aos outros, o que sempre degradará a qualidade de uma decisão coletiva, formulada por pessoas de antemão selecionadas pelo juiz como aptas para o exercício desta nobre função. Por isso, a votação é secreta e o número de jurados é ímpar. Esta argu- mentação é tirada das teorias sobre a psicologia das multidões, que tendiam a ver o júri como um tipo desses aglomerados incontroláveis (SIGHELE, 1954). Nos EUA, a origem da decisão é um grupo que deve resolver suas diferenças pública e internamente, para exprimir-se coletivamente sobre uma verdade que a todos, universalmente, agrega; aqui, o grupo é um conjunto de indivíduos selecionados, que devem manter suas diferenças substantivas para exprimir-se em particular, de acordo, unicamente, com sua consciência individual e inspirados pelos valores cristãos.

IV. CONCLUSÃO: A PARTICULARIZAÇÃO DO ESPAÇO PÚBLICO COMO ESTRATÉGIA DE CONTROLE SOCIAL DIFERENCIADO

Ora, inicialmente, fica claro desta rápida descrição que os procedimentos criminais de produção da verdade, no Brasil, não nascem de uma negociação, que produz verdades para resolver conflitos produzindo novos contratos de ordenamento social, mas pretendem se fundar na descoberta de uma verdade, tarefa que se impõe para a produção da ordem social pela conservação da harmonia em sociedade (NADER, 1996). Tal harmonia deve ser garantida por uma espécie de estratégia de suspeição sistemática, exercitada ora pela autoridade policial, em nome do Estado, ora pelos serventuários e operadores judiciais, constituindo-se em verdadeira estratégia de dominação.

Por outro lado, há uma ambigüidade implícita no sistema, que resulta no uso alternado e alternativo de várias lógicas judiciárias, que se apresentam diferentemente enfatizadas nas diferentes formas que assumem os procedimentos de produção da verdade judiciária criminal: o inquérito policial enfatiza procedimentos de inquirição, o processo judicial enfatiza procedimentos de inquérito, e o tribunal do júri enfatiza procedimentos do sistema de prova legal, ou de justiça divina.

Assim, podemos dizer que o sistema de produção de nossa verdade judiciária criminal não é universal nem unívoco, como afirmam muitas vezes os que o descrevem, teoricamente. Pois não só os princípios de produção da prova são distintos, como também aplicam-se diferentemente a tipos de crimes e de criminosos. Os procedimentos judiciários da polícia se encarregam das investigações sigilosas e preliminares dos crimes e da sua negociação, visando ou a sua 
solução definitiva pela confissão e, posteriormente, seu abafamento, pela repreensão dos conflitos menores - como era o caso dos "crimes de polícia", no tempo do Império; ou ao indiciamento e envio à Justiça dos crimes mais graves ou daqueles - em geral denominados de "criminosos frios e calculistas" - que resistiram à tortura judiciário-policial, ou que se encontram fora do alcance dela em função de sua posição social.

Já o processo judicial se encarrega dos "crimes profissionais", cometidos por aqueles que se dedicam a estas atividades como meio de vida; e o "Tribunal do Júri” se especializa nos "crimes passionais", teoricamente cometidos em defesa da honra - atributo social dos segmentos da sociedade que supostamente dela são portadores naturalmente julgados pela justiça divina, expressa na iluminação da consciência individual dos jurados, sem levar em consideração, obrigatoriamente, testemunhos ou fatos do processo. Em ambos os casos, como já mencionei, a justiça distingue explicitamente entre os acusados, dando-lhes tratamento diferenciado de acordo com sua classe social, através do mecanismo legal da prisão especial.

O contraste com o sistema dos EUA também aponta para uma diferente relação interna entre os operadores do sistema: se lá há uma rivalidade entre acusação e defesa na construção de duas versões que se baseiem em fatos consensuais, decididos em um procedimento controlado por regras estáveis, negociadas e explícitas, há um enfrentamento - chamado de adversarial durante a arbitragem, entre as partes, não se permitindo o fracionamento de nenhum desses agentes do processo. Há também uma tensão entre o Distric Attorney e a polícia, de um lado, e o Judiciário, do outro, pelo monopólio da negociação da verdade. Entretanto, o sistema tende a solucionar pela via da negociação todos os conflitos que a ele se apresentam, enfatizando modelos de normalização e controle, em prejuízo daqueles de repressão e punição, reservados apenas aos desviantes contumazes e incorrigíveis produzidos pelo próprio sistema (KANT DE LIMA, 1997 a).

O sistema brasileiro, ao enfatizar distintas lógicas em procedimentos judiciários hierarquizados diferentemente, incentiva a competição interna pela "melhor" verdade e termina por produzir uma progressiva desqualificação de um sistema sobre o outro. Assim, os conflitos não tendem a ter solução consensual, pois as diferentes verdades foram produzidas de acordo com diferentes critérios de validade, todos legítimos diante do próprio sistema. O que os une, então, não é a lógica comum da produção da prova, mas o ethos da suspeição e da punição sistemática ou do perdão/absolvição dos acusados — cujas "intenções" acabam por valer mais que seus atos.

Em conseqüência, desqualificam-se, reciprocamente, os operadores do sistema, rotulando-se, por exemplo, de advogados "de porta de cadeia" aqueles especialistas em negociações com a polícia; de "advogados de foro" ou "criminalistas", aqueles especialistas nos procedimentos, na maioria informais, dos cartórios do foro, onde se julgam os crimes profissionais; em "advogados de júri", também versados no trato dos cartórios do júri mas, principalmente, treinados na representação pública, na sustentação da versão de seus clientes durante o duelo, ou ordálio, do júri brasileiro. $\mathrm{O}$ mesmo ocorre entre promotores e juízes, cada um a "defender" o sistema de produção da verdade que julga mais eficiente e a "atacar" aqueles que não lhe convencem.

Mais dramática, no entanto, é a situação da polícia: encarregada de descobrir a verdade além de qualquer dúvida, expressa na confissão, vê suas descobertas, validadas pela forma da inquirição a que está submetida, serem anuladas quando submetidas, posteriormente, aos critérios do processo judicial, ou do júri. Situada no lugar mais inferior deste sistema hierárquico, sua verdade também é a que menos vale. Entretanto, não se deve esquecer que é ela que se defronta, no dia a dia, com a população, impregnando-a e por ela sendo impregnada com seus critérios de justiça e de verdade, ao mesmo tempo em que assume, cada vez mais, sua degradação institucional.

A esses problemas acresce o caráter "real" da polícia brasileira, tanto militar como civil: desde D. João VI, cuja coroa enfeita o brasão de nossa Polícia Militar do Estado do Rio de Janeiro, até o ethos repressivo que permeia nossa Polícia Civil, está, sempre, a polícia, a serviço do Rei, do Estado, para conciliar forçadamente ou para reprimir conflitos e não para resolvê-los, garantindo a ordem estatal pública e não negociando e disciplinando, preventivamente, a ordem dos cidadãos.

Confirma-se, assim, de maneira prática e indiscutível, a acepção que a categoria público tem em nosso país, associada à apropriação particu- 
larizada, seja pelo Estado, seja pelos aventureiros que o expropriam. Nem a idéia de public, como bem coletivamente definido e apropriado por um grupo específico, nem a categoria publique, como algo que deve ser igualmente apropriado por todos - como em Re-publique — se assemelham aos significados associados a essa categoria em português. A questão, portanto, não é uma distinção entre o público e o privado, mas uma distinção entre a apropriação universalizada, igual para todos, e a apropriação particularizada, própria de alguns, estar associada, ou não, à esfera pública.

$\mathrm{Na}$ instituição policial, outra característica dessa forma particularizada e segmentar de concepção das instituições e espaços públicos pode ser detectada na própria estrutura interna das organizações policiais. A polícia "civil" está internamente dividida em "delegados" e "tiragem", cujas diferenças salariais são assustadoras para o tipo de tarefas comuns que tem por dever exercer - mas que os delegados justificam, na prática, por serem formados em Direito — que não só não é um saber policial, como este nem mesmo faz parte do currículo dos cursos de Direito - e, assim, poderem operar a tradução entre os dois regimes de verdade, o policial e o judicial; opostos também os "tiras" em "turma da rua" e "turma do cartório", conforme se encarreguem de investigações ou de registros cartoriais, o que define diferentes formas e oportunidades de negociação e remuneração, sempre oficiosas ou ilegais; dividida também a Polícia Militar em estanques categorias de "oficiais" e "praças", com dupla entrada na profissão, tendem estas instituições a reproduzir esta incomunicabilidade de critérios alternativos e alternados internamente, enfatizando formas de socialização informal, não escolar, que produzam e reproduzam socialmente os métodos de construção da verdade a serem exercitados pela corporação, explicita ou implicitamente. Diferentemente da polícia de outros países, nas quais, quando a "teoria na prática é outra", as duas dimensões estão referenciadas ao mesmo regime de verdade, aqui a polícia se move em um outro espaço, "inferior" e controlado por outros princípios, jurídicos ou militares, próprios para reprimir, não para administrar e resolver conflitos.

Esta estrutura tem como resultado a produção de compartimentos estanques de saberes hierarquizados, estando aqueles dos magistrados, por definição, no topo da pirâmide assim constituída, pois deles é a decisão final. A qualidade parti- cularista da apropriação desses saberes é visível em muitos momentos do exercício profissional, a começar pelo próprio acesso às informações processuais e aos textos legais e de doutrina, escassos nos ambientes públicos de acesso universal, como as bibliotecas públicas. O valor positivo que se dá a essa apropriação particularizada contrasta fortemente com o verdadeiro horror que o sistema dos EUA experimenta diante do uso público eficaz do segredo e das informações privilegiadas. Aqui, na verdade, é este acesso privilegiado que cria, com mérito próprio baseado na teia de relações que cada profissional estabeleceu e/ou herdou, o diferencial que se mostra muitas vezes legitimamente decisivo na vitória ou na derrota das causas, pelo domínio das fontes de interpretação autorizada.

A esta "distonia cognitiva", em todas as instituições e níveis, corresponde uma valorização extrema dos intermediários, dos despachantes, alcagüetes da polícia (X-9's), serventuários da Justiça, em especial funcionários cartoriais, que se encarregam não só de permitir — ou não — o acesso às informações processuais de "sua" propriedade - os processos nos cartórios são distribuídos aos funcionários que os guardam particularizadamente - como também de ensinar as diferentes lógicas, implícitas nas práticas judiciárias, a serem apreendidas, caso a caso, pelos operadores, que demandam por eficácia em seus atos junto a sistemas de verdade que possuem diferentes regras, todas também implícitas, para aplicação e validação. Não é sem razão, portanto, que a informatização do Judiciário se faz lentamente. Em um sistema como esse, o papel dos intermediários se torna fundamental para dar acesso às interpretações particulares que orientam os profissionais envolvidos. Este papel social — de mediadores do saber entre usuários e servidores públicos — confere significado e propriedade a sua atuação burocratizante e se constitui na própria razão de sua existência.

Entretanto, esta desqualificação, produzida pelos estilos profissionais respectivamente apropriados para o bom exercício da produção da prova nos diferentes sistemas, não tem apenas consequências internas ao sistema: o próprio sistema, à luz da sociedade como um todo, que demanda critérios universais de aplicação das regras, tidos como os únicos justos e politicamente corretos, perde legitimidade, porque o que vale para um caso e para um agente/acusado não vale para outro. 
O uso alternado e alternativo desses sistemas de verdade caracteriza a operação do sistema com a identidade entre a prestação da justiça e a particularização da aplicação da lei geral. Esta fórmula é própria não só das sociedades mediterrâneas e tradicionais, onde na busca da verdade e das intenções competem diferentes sistemas de honra, que exigem a punição diferenciada do conflito, mas também da codificada civil law tradition, que tem suas disposições gerais elaboradas pelo Legislativo, onde os representantes do povo pretendem controlar o arbítrio do Executivo e do Judiciário, que devem limitar-se, respectivamente, a executá-las e a aplicá-las a casos particulares.

Esta tradição particularista se opõe, aparentemente, aos anseios de universalidade de uma cultura política explícita, de caráter individualista e igualitário, que precisa fundar-se em mecanismos universais de resolução de conflitos pela produção de verdades negociadas. Ao contrário da tradição dos Estados Unidos, onde os princípios processuais são constitucionais e se aplicam universal e localmente, a tensão entre o político e o jurídico, assim, cada vez mais, se faz presente em nossa sociedade, opondo uma concepção de generalidade fundada em diferenças substantivas entre as pessoas e as coisas, próprias dos sistemas hierárquicos e particularistas, a uma universalidade fundada na aplicação local de regras consensuais e na estratificação das igualdades formais, própria dos sistemas individualistas. A questão que se coloca, portanto, não é apenas a das contradições entre as formas de apropriação e uso do público e do privado, mas entre os sistemas de aplicação particularistas ou universalistas das regras gerais ou locais.

Voltando às imagens do início deste texto, é como se vivêssemos com uma pirâmide superposta ao paralelepípedo, todas tracejadas, sem que nenhuma linha se definisse ou se interceptasse verdadeiramente, seccionando uma seção a outra. O espaço público, teoricamente concebido como o locus das regras de aplicação universal para que a comunicação argumentativa se produza sem ruídos, a não ser aqueles produzidos pelo embate dos argumentos padronizados, revela-se impossível e indesejável nessa sistemática construção de verdades orientadas por princípios dissonantes, mas imaginada como harmônica e coerente. Essa harmonia aparente só é exposta quando conflitos, cada vez mais inevitáveis, são publicamente assumidos em função de disputas de poder externas ao sistema, como é o caso recente de mecanismos legislativos imbuídos do discurso político procederem investigações sobre o Judiciário, cuja lógica argumentativa, fundada na interpretação particularizada e na implicitude, encontra dificuldades para se expor aberta e compreensivelmente, em público.

Recebido para publicação em maio de 1999.

Roberto Kant de Lima (kant@web4u.com.br) é Professor Titular do Departamento de Antropologia da Universidade Federal Fluminense (UFF) e pesquisador do CNPq.

\section{REFERÊNCIAS BIBLIOGRÁFICAS}

BOURDIEU, P. 1982. Ce que parler veut dire. L'économie des échanges linguistiques. Paris : Fayard.

1987. A economia das trocas simbólicas. $2^{\text {a }}$ ed. São Paulo : Perspectiva.

BOSCHI, C. 1987. As visitas diocesanas e a Inquisição na Colônia. Revista Brasileira de História, São Paulo, vol. 7, n. 14, p. 151-184, mar./ ago.

DAMATTA, R. 1979. Você sabe com quem está falando? In : R. Carnavais, malandros e heróis. Rio de Janeiro : Zahar.
DUMONT, L. 1974. Casta, racismo e estratificação. In: AGUIAR, N. (org.). Hierarquias em classes. Rio de Janeiro : Zahar.

1985. O individualismo. Uma perspectiva antropológica da ideologia moderna. Rio de Janeiro : Rocco.

FOUCAULT, M. 1974. A verdade e as formas jurídicas. Cadernos da PUC. Rio de Janeiro : PUC-RJ.

1977. Vigiar e punir. História da violência nas prisões. Petrópolis : Vozes.

FRANCO, A. A. 1956. O Júri e a Constituição 
Federal de 1946. Comentários à lei no. 263, de 23 de fevereiro de 1940. $2^{\text {a }}$ ed. Rio de Janeiro : Edição Revista Forense.

GARAPON, A. 1997. Bien juger. Essai sur le rituel judiciaire. Paris : Éditions Odile Jacob.

GEERTZ, C. 1978. A interpretação das culturas. Rio de Janeiro : Zahar.

1998. O saber local. Novos ensaios em antropologia interpretativa. Petrópolis : Vozes.

KANT DE LIMA, R. 1995a. A polícia da cidade do Rio de Janeiro. Seus dilemas e paradoxos. $2^{\mathrm{a}}$ ed. rev. Rio de Janeiro : Forense.

KANT DE LIMA, R. 1995b. Bureaucratic Rationality in Brazil and in the United States: Criminal Justice Systems in Comparative Perspective. In : HESS, D. \& DAMATTA, R. (eds.). The Brazilian Puzzle. Culture on the Borderlands of the Western World. New York : Columbia University Press.

KANT DE LIMA, R. 1997 [1985]. A Antropologia da Academia. Quando os índios somos nós. $2^{\mathrm{a}}$ ed. rev. e aument. Niterói : EDUFF. Tradução para o inglês de David Hess: The Anthropology of the Academy: When $\mathrm{We}$ are the Indians. In : RIPP, A., LAYNE, L. \& HESS, D. (eds.) Knowledge and Society: The Anthropology of Science and Technology, vol. 9, 1992.

KANT DE LIMA, R. 1997b. Polícia e exclusão na cultura judiciária. Revista de Sociologia da USP, São Paulo, vol. 9, n. 1, p. 169-183, maio.

LÉVI-STRAUSS, C. 1950. Introduction à l'oeuvre de Marcel Mauss. In : MAUSS, M. Sociologie et Anthropologie. Paris : PUF.

. 1970. Antropologia estrutural. $2^{\text {a }}$ ed. Rio de Janeiro : Tempo Brasileiro.

LINDHOLM, C. \& HALL, J. A. 1997. Is the United States Falling Apart? Journal of the American Academy of Arts and Sciences, Cambridge, vol. 126, n. 2, p. 183-208, Spring.
In : Human Diversity, Daedalus, Spring. Arquivado como vol. 126, n. 2, de Proceedings of the AAAS.

MALATESTA, N. F. 1911. A lógica das provas em matéria criminal. Rio de Janeiro : Livraria Cruz Coutinho, 2 vols.

MAINE, H. S. 1861 [1908]. Ancient Law. London : John Hurray.

MARGARINOS TORRES 1939. Processo Penal do Jury no Brasil. Rio de Janeiro : Livraria Jacintho.

MAUSS, M. 1950. Sociologie et Anthropologie. Paris : Presses Universitaires de France.

MENDES DE ALMEIDA JÚNIOR, J. 1920. $O$ processo criminal brazileiro. $3^{\mathrm{a}}$ ed. aument. Rio de Janeiro : Typographia Baptista de Souza.

NADER, L. 1996. A civilização e seus negociadores: a harmonia como técnica de pacificação. In : Anais da XIX Reunião Brasileira de Antropologia. Niterói : Associação Brasileira de Antropologia/Departamento de Antropologia da Universidade Federal Fluminense.

SIGHELE, S. 1954. A multidão criminosa. Ensaio de psicologia coletiva. Rio de Janeiro : Organização Simões.

STEINBERG, A. 1984. From Private Prosecution to Plea Bargaining: Criminal Prosecution, the District Attorney, and American Legal History. Crime and Delinquency, vol. 30, n. 4, p. 568592, 1984.

STEINBERG, A. 1989. The Transformation of Criminal Justice. Chapel Hill : University of North Carolina Press.

TORRES, M. 1939. Processo penal do jury no Brasil. Rio de Janeiro : Livraria Jacintho Editora.

TURNER, V. 1974. O processo ritual. Petrópolis : Vozes. 